\title{
Gestão democrática na mesorregião Oeste Maranhense: enfoques e destaques nas leis dos Sistemas Municipais de Educação ${ }^{1}$
}

\section{Democratic management in mesoregion west of Maranhão: approaches and highlights in the laws of Municipal Education Systems}

\author{
Maria José Pires Barros Cardozo* \\ Maria Lília Imbiriba Sousa Colares**
}

\begin{abstract}
RESUMO
O presente artigo analisa questões referentes aos Sistemas Municipais de Educação (SME) na Mesorregião Oeste Maranhense, em especial o princípio da gestão democrática nos municípios que institucionalizaram os seus SME. As questões e inferências aqui apresentadas decorrem de pesquisa bibliográfica e documental realizada no pós-doutoramento do Programa de Pós-graduação em Educação da Universidade Federal do Oeste do Pará (Ufopa). Discorre-se sobre alguns aspectos e questões teóricas e legais que fundamentam a concepção de sistema educacional e a gestão democrática como premissas que orientam a criação dos SME. Infere-se que, embora os municípios gozem da prerrogativa de criarem seus SME, na mesorregião Oeste Maranhense, apenas 8 dos 52
\end{abstract}

1 Trabalho financiando pela Fundação de Amparo à Pesquisa e ao Desenvolvimento Científico e Tecnológico do Maranhão (FAPEMA) mediante a concessão de bolsa pesquisador no período de agosto de 2016 a agosto de 2107 e Coordenação de Aperfeiçoamento de Pessoal de Nível Superior/Conselho Nacional de Desenvolvimento Científico e Tecnológico (CAPES/CNPQ) mediante concessão de bolsa de pós-doutoramento no período de setembro de 2017 a agosto de 2108 no Programa de Pós-graduação em Educação da Universidade Federal do Oeste do Pará (UFOPA), sob a supervisão da Profa. Dra. Maria Lília Imbiriba Sousa Colares.

*Universidade Federal do Maranhão. São Luís, Maranhão, Brasil. E-mail: isoamri@bol. com.br. https://orcid.org/0000-0003-0059-7006.

** Universidade Federal do Oeste do Pará. Santarém, Pará, Brasil. E-mail: lilia.colares@ hotmail.com. https://orcid.org/0000-0002-5915-6742. 
institucionalizaram seus sistemas com base em leis específicas, abstendo-se dos dispositivos legais que dispõem sobre a definição e normatização de legislação específica e diretrizes educacionais que possibilitem a ampliação e fortalecimento dos espaços e mecanismos de participação, consolidando a gestão democrática da educação municipal.

Palavras-chave: Sistema Municipal de Educação. Gestão democrática. Participação.

\begin{abstract}
This article aims to examine issues relating to Municipal Education Systems (EMS) in mesoregion west of Maranhão, in particular the principle of democratic management in the municipalities that institutionalized their EMS. The questions and inferences presented here is bibliographical research and post-doctoral documentary in the post-graduate program in education of the Federal University of the West of Pará (Ufopa). This article talks on some aspects and theoretical and legal issues that underlie the design of educational system and the democratic administration as premises that guide the creation of EMS. It is infered that, although municipalities enjoy the prerogative to create your EMS, in mesoregion west of Maranhão, only 8 of the 52 institutionalized their systems based on specific laws, refraining from legal devices that feature on the definition and standardization of specific legislation and educational guidelines that allow the expansion and strengthening of the spaces and mechanisms for participation, consolidating the democratic management of municipal education.
\end{abstract}

Keywords: Municipal Education System. Democratic Management. Participation.

\title{
Introdução
}

Este artigo é decorrente da pesquisa de pós-doutorado realizada no período de setembro de 2017 a agosto de 2018 na Ufopa, é também um recorte dos estudos em andamento no projeto de pesquisa intitulado "Gestão democrática do ensino público: mapeamento das bases normativas e das condições políticoinstitucionais dos sistemas municipais de ensino do Maranhão", desenvolvido em rede com as seguintes instituições de ensino superior: Universidade Federal do Maranhão (UFMA), Universidade do Oeste de Santa Catarina (UOESC), Universidade Federal de Santa Maria (UFSM), Universidade Estadual do Piauí 
(UEPI), Universidade Federal de Tocantins (UFT), Universidade Federal do Ceará (UFC), Universidade Estadual de Ponta Grossa (UEPG) e Universidade Estácio de Sá do Rio de Janeiro. Cada instituição está analisando o quadro normativo e as condições político-institucionais relativos à gestão democrática do ensino público no âmbito dos Sistemas Municipais de Educação (SME) em seus respectivos estados, tendo como base as leis de criação dos SME. Os dados aqui apresentados decorrem do projeto de pesquisa "Gestão democrática do ensino público: mapeamento das bases normativas e das condições políticoinstitucionais dos sistemas municipais na mesorregião Oeste do Maranhão", realizado no pós-doutoramento acima referido.

Do ponto de vista metodológico, realizaram-se estudos bibliográficos para o aprofundamento teórico a fim de contribuir para uma melhor compreensão e análise dos princípios e pressupostos da gestão democrática do ensino público; levantamento, sistematização e análise de documentos referentes à base legal relativa à normatização da gestão democrática do ensino público no âmbito dos sistemas municipais de educação da mesorregião investigada (Lei Orgânica Municipal, Lei de Criação do SME e Lei de Criação do Conselho Municipal de Educação - CME); e identificação e análise de princípios, estruturas, espaços e mecanismos institucionalizados de participação, estabelecidos nas normas dos sistemas municipais de ensino.

Discorre-se sobre algumas questões teóricas e legais que fundamentam os SME no Brasil a partir do reconhecimento legal na Constituição Federal (CF) de 1988, quando os municípios foram considerados como entes federados, com autonomia para constituírem seus SME. Analisa-se o princípio da gestão democrática nos municípios da mesorregião Oeste Maranhense que institucionalizaram os seus SME num contexto de expansão e transferência de responsabilidades para as esferas municipais, no âmbito do regime de colaboração posto na CF de 1988 e na Lei de Diretrizes e Bases da Educação, a LDB nº 9.394/1996, e do PNE Lei $n^{\circ} 13.005$, de 2014.

\section{Gestão democrática como princípio teórico e legal}

A questão das políticas públicas se coloca no âmbito da repartição de competências (concorrentes-legislativas e comuns-administrativas) em textos legislativos e políticas situados na relação centralização/descentralização/centralização entre a união, os estados e os municípios. No que se refere à educação, Abrúcio (2010, p. 40), pontua três aspectos que devem ser considerados: 
[...] a descentralização, em especial na sua tradução como municipalização, forma tomada como capaz de gerar tanto a melhoria da gestão como a democratização do sistema de ensino; a previsão de políticas nacionais orientadoras e planejadoras nas formas da LDB e do Plano Nacional de Educação; e um diferenciador da educação frente aos outros setores, a proposição de um regime de colaboração entre os níveis de governo como instrumento que garantiria a boa implementação de da política em todos os seus ciclos, em especial na educação básica.

Desse modo, o regime federativo brasileiro, sobretudo a partir da CF de 1988, dispôs sobre a redistribuição do poder através da repartição horizontal e vertical de competências, delegando à União competências de interesse nacional; aos Estados de interesse regional; e aos Municípios, de interesse local. A repartição horizontal relaciona-se ao campo material e legislativo; aos Estados, as remanescentes; e aos Municípios, as definidas indicativamente. Já a repartição vertical é prevista no artigo 23 e refere-se à atuação concorrente dos entes federados em domínios de execução comum e pode ser concomitante e cooperativa entre a União, Estados, Distrito Federal e Municípios.

Com base em princípios democráticos, a CF de 1988 delega aos municípios a prerrogativa de criação dos seus sistemas de educação conforme estabelece o artigo 18: "a organização político-administrativa da República Federativa do Brasil compreende a União, os Estados, o Distrito Federal e os Municípios, todos autônomos, nos termos desta Constituição" (BRASIL, 1988). A autonomia é reforçada no artigo 211, que estabelece o seguinte:

A União, os Estados, o Distrito Federal e os Municípios organizarão, em regime de colaboração seus sistemas de ensino [...]

$\S 4^{\circ} \mathrm{Na}$ organização de seus sistemas de ensino, os estados e os municípios definirão formas de colaboração, de modo a assegurar a universalização do ensino obrigatório (BRASIL, 1988).

Do mesmo modo, a LDB/1996 dispôs no artigo $8^{\circ}$ que a União, os Estados, o Distrito Federal e os Municípios organizarão, em regime de colaboração, os respectivos sistemas de educação. Para os Municípios, o artigo 11 estabelece que estes incumbir-se-ão de: organizar, manter e desenvolver os órgãos e instituições oficiais dos seus sistemas de ensino, integrando-os às políticas e aos planos educacionais da União e dos Estados; e baixar normas complementares para os seus sistemas de ensino (BRASIL, 1996). 
Para os Municípios, essa legislação possibilitou a prerrogativa de participarem do regime de colaboração, a inserção da Educação Municipal como um capítulo de suas Leis Orgânicas, a elaboração dos Planos Municipais de Educação (PME), e a instituição dos SME e dos CME, atendendo, assim, ao preceito constitucional previsto no artigo 211, que dispõe sobre a organização, em regime de colaboração, dos sistemas de ensino da União, dos Estados e Municípios.

Nesse contexto, é relevante a compreensão da concepção de sistema educacional, que, conforme Saviani (2010), compreende uma unidade de elementos intencionalmente reunidos de maneira a se chegar a um conjunto coerente e operante, capaz de corresponder às aspirações e aos imperativos da sociedade civil e política. Esta unidade de elementos dotados de intencionalidades conforma a definição de finalidades e objetivos comuns para o conjunto do sistema. Assim, trata-se "de unidade da variedade e não unidade da identidade" (SAVIANI, 2010, p. 381). Desse modo, o sistema educacional "articula uma variedade de elementos que, ao se integrarem ao todo, nem por isso perdem a própria identidade; ao contrário, participam do todo, integram o sistema na forma de suas respectivas especificidades" (SAVIANI, 2010, p. 381).

Saviani (2010) acrescenta, ainda, que a concepção de sistema educacional no Brasil relaciona-se com o regime federativo e com a expectativa de colaboração entre os entes federados, conforme dispõe a LDB n ${ }^{\circ}$ 9.394/1996, no artigo $8^{\circ}$ :

\begin{abstract}
A União, os Estados, o Distrito Federal e os Municípios organizarão, em regime de colaboração, os respectivos sistemas de ensino.

$\S 1^{\circ}$ Caberá à União a coordenação da política nacional de educação, articulando os diferentes níveis e sistemas e exercendo função normativa, redistributiva e supletiva em relação às demais instâncias educacionais. $\S 2^{\circ}$ Os sistemas de ensino terão liberdade de organização nos termos desta Lei (BRASIL, 1996).
\end{abstract}

De acordo com a lei acima mencionada, o município poderá optar entre três possibilidades no que se refere à organização do seu sistema de educação, conforme expressa o parágrafo único do artigo 11: instituir o próprio Sistema de Ensino; integrar-se ao Sistema Estadual de Ensino; compor com o Estado um sistema único de educação básica (BRASIL, 1996). Ao fazer a opção de criar o seu SME, o município deverá atender ao previsto no PNE Lei $\mathrm{n}^{\circ} 13.005$, de 2014, no que concerne à elaboração de seu PME, tendo como base o avanço da dinâmica de democratização do planejamento e da gestão da educação municipal. 
Para tanto, Dourado e Amaral Nelson (2011) asseveram que a gestão democrática poderá contribuir para a efetivação de políticas e planos dos sistemas e escolas que visem a melhoria da qualidade da educação pública. Para eles, é necessário compreender a gestão democrática como:

[...] espaço de deliberação coletiva (estudantes, funcionários, professores, pais ou responsáveis), precisa ser assumida como base para a melhoria da qualidade da educação e aprimoramento das políticas educacionais, enquanto políticas de Estado articuladas com as diretrizes racionais para todos os níveis e modalidades de educação/ensino (DOURADO; AMARAL NELSON, 2011, p. 303).

Corrobora-se a concepção apontada pelos autores supracitados e se reafirma a gestão democrática como:

[...] processo de aprendizagem e de luta política que não se circunscreve aos limites da prática educativa mas vislumbra, nas especificidades dessa prática social e de sua relativa autonomia, a possibilidade de criação de canais de efetiva participação e de aprendizado do "jogo" democrático $\mathrm{e}$, consequentemente, do repensar das estruturas de poder autoritário que permeiam as relações sociais e, no seio dessas, as práticas educativas. (DOURADO, 2008, p. 79).

Embora com limitações, a LDB n ${ }^{\circ}$ 9.394/1996 abriu algumas possibilidades para a gestão democrática da educação, ao reforçar o princípio constitucional dispondo no artigo $3^{\circ}$ que o ensino será ministrado tendo como princípio "a gestão democrática do ensino público na forma desta Lei e da legislação dos sistemas de ensino" (BRASIL, 1996, p. 47). Já o artigo 14 prevê que "os sistemas de ensino definirão as normas da gestão democrática do ensino público na educação básica, de acordo com suas peculiaridades" (BRASIL, 1996, p. 52).

Mesmo que o princípio da gestão democrática da educação pública esteja garantido nos instrumentos legais, considera-se que o seu processo de materialização é contraditório, lento e atravessado por conflitos, avanços e retrocessos, pois ainda se vivenciam práticas autoritárias e clientelistas do mandonismo local e regional e da hegemonia da elite sobre as classes populares.

Para Cabral Neto e Castro (2014, p. 750): 
O fulcro desse processo está centrado em uma dinâmica, na qual se materializa uma desconcentração de responsabilidades em direção a ponta do sistema e não do poder de decisão dos níveis hierarquicamente inferiores da organização administrativa. Com essas características, a participação se metamorfoseia em uma técnica de gestão propiciadora de coesão e consenso, despolitizando, assim, o processo de participação dos sujeitos sociais na formulação, implementação e avaliação da política.

Desse modo, a gestão dos SME tem o desafio de suplantar os procedimentos de racionalização e da busca por resultados, em face à diminuição dos investimentos, e superar a cultura do clientelismo e do patrimonialismo, práticas que ainda são presentes em vários municípios brasileiros, em especial nos maranhenses, cujos arranjos políticos são caracterizados pela centralização do poder local a fim de que os processos participativos permitam aos sujeitos envolvidos perceberem a necessidade de ruptura de práticas que considerem as decisões individuais e não coletivas.

A participação que preserve os interesses coletivos deve compreender o

[...] Estado ampliado, portanto, resultante da articulação e disputa entre sociedade civil e sociedade política e, nesse cenário, não se reduzindo ao governo, compreendendo-se que o caminho para buscar romper com a tradição histórica do Estado brasileiro, passa pela efetiva participação da sociedade civil e política (DOURADO, 2011, p. 52).

Nessa perspectiva, os mecanismos que possibilitam a participação coletiva não podem permitir práticas que provoquem seu esvaziamento, ou seja, governantes que estimulem no âmbito do discurso a participação, mas não atendam às demandas da sociedade civil organizada, controlem os movimentos sociais e criem estratégias participativas tuteladas para legitimar as ações da administração pública. Portanto, a vontade política dos que compõem a administração pública merece atenção, uma vez que a implementação das políticas educacionais aliada ao cumprimento das decisões tomadas coletivamente é fundamental para ensejar processos participativos que contribuem para a gestão democrática da educação pública em todas as etapas e modalidades, tanto no âmbito dos sistemas como das instituições educativas. 


\section{Análise do princípio da gestão democrática nas leis do SME na Mesorregião Oeste Maranhense}

O estado do Maranhão situa-se no Nordeste Oriental, numa área de transição entre o Nordeste e a Região Norte (Meio Norte). Do ponto de vista geográfico, o IBGE divide o estado em cinco mesorregiões: Centro, Leste, Oeste, Norte e Sul. O Maranhão ocupa uma área de 331.983,293 km², sendo o $2^{\circ}$ maior em extensão do Nordeste e o $8^{\circ}$ do Brasil; $80 \%$ do seu território está incluído na Amazônia Legal. Segundo dados do Instituto Brasileiro de Geografia e Estatística (IBGE), em 2017, contava com uma população de 7.000.229 de habitante (IBGE, 2017a).

A Mesorregião Oeste Maranhense, objeto de estudo neste trabalho, é uma das cinco mesorregiões maranhenses, conforme divisão do IBGE (2017a), composta por 52 municípios, que ocupam uma área de $86.550 \mathrm{~km}^{2}$, com 1.414.734 habitantes. Divide-se em três microrregiões: Gurupi, Pindaré e Imperatriz, é também denominada de região pré-amazônica, conforme se pode observar no mapa a seguir.

MAPA 1 - DIVISÃO DO ESTADO DO MARANHÃO EM MESORREGIÕES SEGUNDO O IBGE

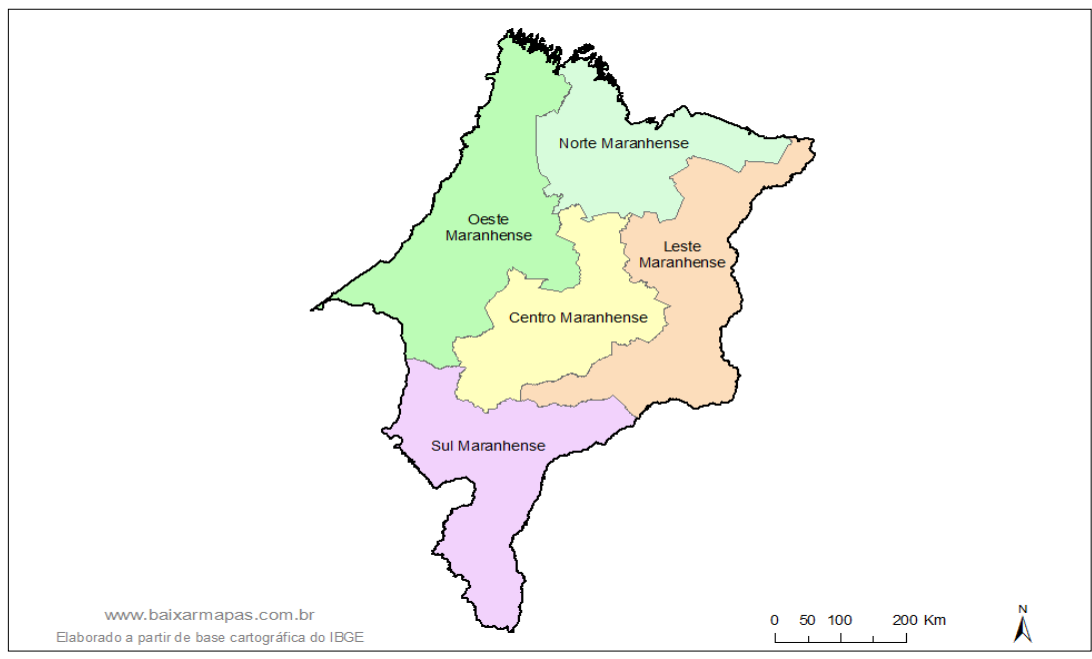

FONTE: IBGE, 2017b. 
No que se refere à criação dos SME, o quadro abaixo revela que dos 52 que compõem a mesorregião Oeste, apenas 08 municípios instituíram em lei específica.

QUADRO 1 - INSTITUCIONALIZAÇÃO DOS SISTEMAS MUNICIPAIS DE ENSINO DA MESORREGIÃO OESTE MARANHENSE

\begin{tabular}{|c|c|c|c|c|}
\hline & Município & Ato legal vigente & No do ato/ano $^{\circ}$ & $\begin{array}{c}\text { Ano da } \\
\text { institucionalização }\end{array}$ \\
\hline 1. & Açailândia & Lei & 322 & 2009 \\
\hline 2. & Alto Alegre do Pindaré & Lei & 059 & 2003 \\
\hline 3. & Governador Nunes Freire & Lei & 007 & 2006 \\
\hline 4. & Imperatriz & Lei & 901 & 1999 \\
\hline 5. & Lago da Pedra & Lei & 258 & 2010 \\
\hline 6. & Nova Olinda do Maranhão & Lei & 084 & 2010 \\
\hline 7. & Santa Luzia & Lei & 311 & 2006 \\
\hline 8. & Turiaçu & Lei & 482 & 2003 \\
\hline
\end{tabular}

FONTE: Elaboração própria com base na legislação pesquisada.

Esses dados podem retratar tanto as limitações econômicas que o estado enfrenta quanto as características políticas que predominaram no Maranhão por mais de quarenta décadas do coronelismo e da oligarquia sarneísta, conforme expressa Fausto (2008, p. 173), "o Estado caracterizava-se como um feudo político, informalmente transmitido por herança, sendo este um meio "natural" de preservação de poder, este de fato, não de direito", refletia, assim, a antiga estrutura política da primeira república brasileira, traço diretamente vinculado à estrutura socioeconômica "tradicional do país, fundamentada em grupos de parentela que são ao mesmo tempo grupos de parentesco de sangue com suas alianças e grupos associados econômico-politicamente" (FAUSTO, 2008, p. 173-174). Essa situação ainda é vivenciada em alguns municípios maranhenses, conforme expressa o mapa a seguir sobre a criação dos SME na mesorregião Oeste do estado. 
MAPA 2 - CRIAÇÃO DOS SISTEMAS MUNICIPAIS DE EDUCAÇÃO-MARANHÃO MESORREGIÃO OESTE

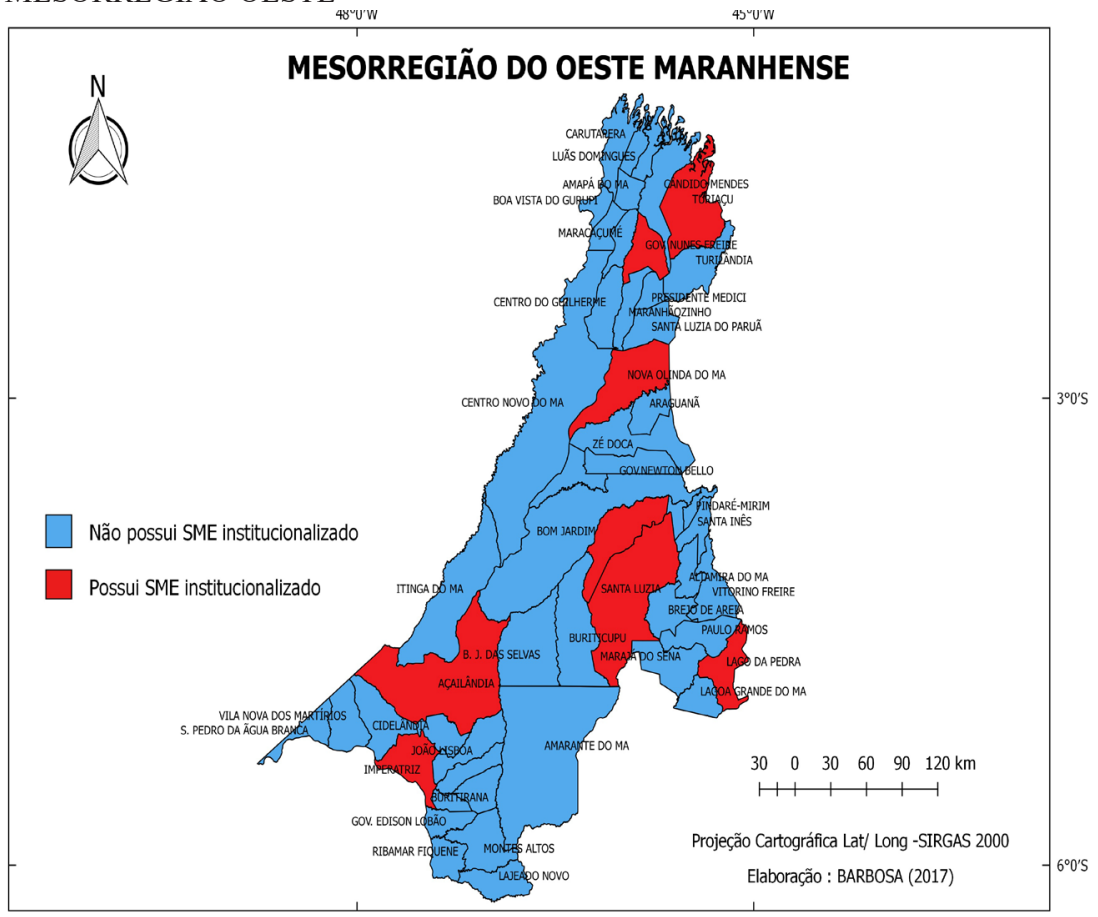

FONTE: Barbosa (2017).

O mapa acima indica que do total de municípios pesquisados nessa mesorregião identificou-se que apenas 08 (oito) institucionalizaram os SME, correspondendo ao percentual de 15,3.

No que concerne à participação, a análise das legislações dos SME permitiu sintetizar o seguinte quadro: 
QUADRO 2 - PRINCÍPIOS DE GESTÃO DEMOCRÁTICA DO ENSINO CONFORMADOS NA LEGISLAÇÃO DOS SISTEMAS DE ENSINO DOS MUNICÍPIOS DA MESORREGIÃO OESTE MARANHENSE- PARTICIPAÇÃO

\begin{tabular}{|c|c|c|c|c|c|c|}
\hline \multirow{2}{*}{ MUNICÍPIO } & \multicolumn{2}{|c|}{$\begin{array}{c}\text { Comunidade escolar } \\
\text { no conselho escolar }\end{array}$} & \multicolumn{2}{c|}{$\begin{array}{c}\text { Profissionais no } \\
\text { PPP }\end{array}$} & \multicolumn{2}{c|}{$\begin{array}{c}\text { Comunidade no } \\
\text { planejamento da } \\
\text { educ. municipal }\end{array}$} \\
\cline { 2 - 7 } & Sim & Não & Sim & Não & Sim & Não \\
\hline Açailândia & & $\mathrm{X}$ & & $\mathrm{X}$ & & $\mathrm{X}$ \\
\hline Alto Alegre do Pindaré & $\mathrm{X}$ & & $\mathrm{X}$ & & $\mathrm{X}$ & \\
\hline Governador Nunes Freire & & $\mathrm{X}$ & & $\mathrm{X}$ & & $\mathrm{X}$ \\
\hline Imperatriz & $\mathrm{X}$ & & $\mathrm{X}$ & & $\mathrm{X}$ & \\
\hline Lago da Pedra & & $\mathrm{X}$ & & $\mathrm{X}$ & & $\mathrm{X}$ \\
\hline Nova Olinda do Maranhão & & $\mathrm{X}$ & & $\mathrm{X}$ & & $\mathrm{X}$ \\
\hline Santa Luzia & $\mathrm{X}$ & & $\mathrm{X}$ & & $\mathrm{X}$ & \\
\hline Turiaçu & $\mathrm{X}$ & & $\mathrm{X}$ & & $\mathrm{X}$ & \\
\hline
\end{tabular}

FONTE: Elaboração própria a partir da legislação municipal.

Quanto ao princípio da participação da comunidade escolar no conselho escolar, dos profissionais da educação na elaboração do Projeto Político-Pedagógico e da comunidade no planejamento da educação municipal, o quadro acima revela que apenas $50 \%$ dos municípios pesquisados mencionaram a participação da comunidade, planejamento participativo e descentralização do processo de gestão educacional e do orçamento. Já quando se referem à eleição de gestores, apenas 03 (três) municípios citaram esse mecanismo e somente 01 (um) mencionou o Fórum Municipal de Educação-FME.

Esses dados indicam que devemos estar atentos para as tentativas que o governo faz para estreitar a esfera pública, ou seja:

[...] transformá-la em assunto privado seu, e, para isso, a repelir para a vida privada as intervenções e os lugares de intervenção dos atores não estatais. Assim a democracia, longe de ser a forma de vida dos indivíduos empenhados em sua felicidade privada, é o processo de luta contra essa privatização, o processo de ampliação dessa esfera. Ampliar a esfera pública [...]. Significa lutar contra a divisão do público e do privado que garante a dupla dominação da oligarquia no Estado e na sociedade (RANCIÈRE, 2014, p. 72).

Os dados acima revelam, ainda, que a menção de somente 03 (três) municípios com a participação da comunidade na escolha dos dirigentes 
escolares, por meio da eleição direta, ainda é um desafio a ser superado, tanto na Mesorregião Oeste Maranhense como nas demais, pois a eleição dos dirigentes é um exercício democrático importante para o fortalecimento da gestão democrática, embora não seja garantia efetiva de democratização da gestão escolar, conforme aponta Dourado (2011, p. 102):

Embora as eleições se apresentem como um legítimo canal na luta pela democratização da escola e das relações sociais mais amplas - e não o único - é necessário não perdermos de vista as limitações do sistema representativo numa sociedade de classes, assentada em interesses antagônicos e irreconciliáveis.

Quanto aos espaços e mecanismos de participação, previstos nas Leis de Criação dos SME dos municípios investigados, o quadro abaixo sintetiza o seguinte:

QUADRO 3 - SÍNTESE DOS ESPAÇOS E MECANISMOS DE PARTICIPAÇÃO DEFINIDOS NA LEGISLAÇÃO DOS SISTEMAS DE ENSINO DOS MUNICÍPIOS DA MESORREGIÃO OESTE MARANHENSE

\begin{tabular}{|c|c|c|c|c|c|c|c|c|}
\hline \multirow{2}{*}{ MUNICÍPIO } & \multicolumn{2}{|c|}{ CME } & \multicolumn{2}{c|}{ PME } & \multicolumn{2}{c|}{$\begin{array}{c}\text { Conselho } \\
\text { Escolar }\end{array}$} & \multicolumn{2}{c|}{$\begin{array}{c}\text { Grêmio } \\
\text { Estudantil }\end{array}$} \\
\cline { 2 - 10 } & Sim & Não & Sim & Não & Sim & Não & Sim & Não \\
\hline Açailândia & $\mathrm{X}$ & & & $\mathrm{X}$ & & $\mathrm{X}$ & & $\mathrm{X}$ \\
\hline Alto Alegre do Pindaré & $\mathrm{X}$ & & $\mathrm{X}$ & & $\mathrm{X}$ & & $\mathrm{X}$ & \\
\hline Governador Nunes Freire & $\mathrm{X}$ & & & $\mathrm{X}$ & & $\mathrm{X}$ & & $\mathrm{X}$ \\
\hline Imperatriz & $\mathrm{X}$ & & $\mathrm{X}$ & & $\mathrm{X}$ & & & $\mathrm{X}$ \\
\hline Lago da Pedra & $\mathrm{X}$ & & & $\mathrm{X}$ & & $\mathrm{X}$ & & $\mathrm{X}$ \\
\hline Nova Olinda do Maranhão & $\mathrm{X}$ & & & $\mathrm{X}$ & & $\mathrm{X}$ & & $\mathrm{X}$ \\
\hline Santa Luzia & $\mathrm{X}$ & & $\mathrm{X}$ & & $\mathrm{X}$ & & $\mathrm{X}$ & \\
\hline Turiaçu & $\mathrm{X}$ & & $\mathrm{X}$ & & & $\mathrm{X}$ & & $\mathrm{X}$ \\
\hline
\end{tabular}

FONTE: Elaboração própria a partir da legislação municipal.

De acordo com o quadro acima, evidencia-se que todos os municípios que institucionalizaram seus SME citam o CME como espaços da gestão democrática, porém apenas $50 \%$ mencionam em suas leis de criação do SME o plano municipal; e apenas 02, o grêmio estudantil. Destaca-se, ainda, que somente 01 município citou o Fórum Municipal de Educação-FME e a Conferência Municipal de Educação. Desse modo, ressalta-se a importância 
que esses espaços democráticos possuem na formulação, implementação, monitoramento, avaliação e controle social das políticas públicas locais. Portanto, é necessário fortalecer esses espaços para não sermos submetidos as novas pressões ideológicas das classes dominantes que exigem "não somente a alienação do poder "democrático" mas a separação clara entre a "democracia" e o "demos" - ou, no mínimo, o afastamento decidido do poder popular como principal critério de valor democrático" (WOOD, 2011, p. 196).

Em relação aos CME, é importante ressaltar-se que a existência legal desse mecanismo pode não significar autonomia, composição plural e paritária e exercício pleno de suas funções deliberativas, consultivas, fiscalizadoras e de controle social, pois na maioria das vezes a existência do CME não significa mudanças nas tradicionais formas de participação tuteladas e subordinadas a que historicamente sujeitos foram chamados a participarem como dádiva e não como direitos de cidadania. Muitos membros dos conselhos participam para referendar demandas corporativas e para fortalecer posturas centralizadas, ou ainda para dar número e quorum necessário, mas não para mudar ou construir estruturas legítimas de participação (GONH, 2008).

Registra-se, também, que somente 02 (dois) municípios mencionaram grêmios estudantis e (03) conselhos escolares. Em relação ao grêmio estudantil, destaca-se que a falta de menção nas Leis dos SME não implica em fragilidade da legislação, uma vez que as prioridade dos municípios referem-se à oferta da Educação Infantil e do Ensino Fundamental, e os grêmios são mais frequentes no Ensino Médio. Contudo, o incentivo à formação política de representantes de turma no ensino fundamental e a participação dos alunos nos conselhos escolares contribui para a gestão democrática da escola. Já a ausência do reconhecimento dos conselhos escolares nas leis analisadas como instrumentos de participação, desconsidera que:

[...], a participação requer o sentido da construção de algo que pertence a todos e que tem diretamente a ver com a qualidade de vida de cada um, seja no sentido da realização pessoal, seja pelos benefícios sociais que dela advém. O compromisso, que gera a participação, requer a repartição coletiva do sucesso, não apenas da responsabilidade (BORDIGNON; GRACINDO, 2000, p. 171).

A análise da legislação dos SME dos 08 municípios da Mesorregião Oeste Maranhense possibilitou inferir que o protagonismo municipal é influenciado por diversos fatores, como: o grau de articulação social e política das comunidades 
locais, a vontade política das administrações públicas, o desenho institucional das políticas educacionais, a capacidade de realizar políticas participativas e, sobretudo, a forma como os governantes conduzem as políticas públicas no âmbito de cada município. Acrescenta-se, ainda que a "orientação de políticas públicas de educação para os interesses coletivos significará um mecanismo importante para a valorização dos espaços municipais, quase sempre fadados a integrarem-se a políticas homogeneizadas" (NARDI, 2006, p. 64), em destaque para as recomendadas pelos organismos internacionais, que na maioria das vezes não levam em consideração as diversidades municipais.

Desse modo, embora os SME constituam instância de gestão da educação municipal com base constitucional, ou seja, como ente federativo autônomo, com caráter de pessoa jurídico-política de direito interno e com autonomia, muitos municípios maranhenses ainda não se dispuseram ao cumprimento do disposto na $\mathrm{CF}$, pois dos 52 que compõe a mesorregião analisada apenas 08 constituíram os seus SME em lei específica, embora essa prerrogativa não impeça que esse ente federado possa elaborar o seu Plano Municipal de Educação-PME, que, por sua vez, deveria constar na lei de criação do SME.

\section{Considerações finais}

Ao longo deste artigo, procurou-se mostrar como o princípio da gestão democrática expressa-se nas leis de criação dos SME nos municípios da Mesorregião Oeste Maranhense. Os dados e análises permitem inferir que a criação do SME poderá possibilitar aos municípios a organização, o planejamento e a avaliação das ações educacionais de suas competências normativas. Para tanto, a autonomia não deve ser restrita aos preceitos legais, mas abranger aspectos administrativos, técnicos e financeiros, ou seja, revelar a capacidade e o compromisso dos governantes municipais de atuar juntos com os $\mathrm{CME}$ e demais fóruns ligados à educação pública para deliberarem conjuntamente sobre a política educacional.

Para tanto, é relevante que o regime federalista, por via da descentralização, seja acompanhado pelo repasse de recursos aos municípios e pelo planejamento articulado dos entes federados "não só para construir consensos sobre objetivos gerais, mas principalmente para fixar instrumentos e metas de gestão educacional, com a definição de como isso funcionará na engrenagem federativa brasileira" (ABRÚCIO, 2010, p. 66).

Os resultados da pesquisa permitem destacar que há necessidade de superação das concepções e práticas autoritárias, burocratizadas e centralizadoras 
ainda presentes na cultura política brasileira, que não descentralizam o poder, não compartilham decisões nem permitem processos e espaços participativos e coletivos. A superação desses desafios poderá construir e configurar a gestão democrática como forma de participação ativa e de controle social, no sentido de uma educação pública de qualidade social.

Quanto à gestão democrática, destaca-se que a legislação assegura esse princípio na organização da educação brasileira, assim, a participação deve ser estimulada de modo a possibilitar a ampliação dos espaços e mecanismos que promovam mais engajamento coletivo na formulação, acompanhamento e controle social das políticas públicas municipais. Além disso, os processos participativos devem superar a tutela e os desencantos produzidos pela ideologia meritocrática, baseada em resultados, individualismos e competições, defendidos pelo mercado.

A inclusão do princípio democrático abriu e garantiu espaços para professores, estudantes e comunidades escolares reivindicarem e organizarem experiências de gestão com processos mais participativos e ampliados de tomadas de decisões e fizeram emergir outras tensões que gravitam em torno dos seguintes eixos: conselhos escolares e participação, descentralização/centralização, autonomia, projeto político-pedagógico e eleições de gestores. Somente a institucionalização de um ou outro desses componentes, entretanto, não é garantia de democratização de fato, pois se torna necessário atentar para a ideologia impregnada no discurso de apropriação dos apelos sociais em favor dos preceitos do sistema socioeconômico, bem como para o fato de que a lei, por si só, não é garantia de direito efetivo. O contexto da aplicabilidade dessa lei e os atores envolvidos nesse processo têm importância preponderante para que a democracia se concretize, atendo-se aos preceitos implícitos nos discursos ou às reivindicações reais dos movimentos e das necessidades dos sistemas e das escolas.

A democratização da gestão escolar é fundamental para que a escola realize o seu trabalho, oferecendo um ensino de qualidade referenciada que recoloque a questão da função política e social da escola, no contexto dos interesses diferenciados que marcam a sociedade e a educação brasileira.

Em síntese, no âmbito dos municípios, o SME e o CME são fundamentais para o processo de planejamento municipal, uma vez que o CME poderá ser o mobilizador do processo de diálogo entre a sociedade civil e a política e, em articulação com os fóruns municipais e outros instrumentos de acompanhamento e controle social da educação, ambos poderão contribuir para a elaboração, acompanhamento e avaliação do Plano Municipal de Educação (PME). Este último, por sua vez, é o instrumento de gestão do município que efetiva as metas e diretrizes previstas no PNE - eixo da política educacional brasileira - e no Plano Estadual de Educação (PEE), conforme o regime de colaboração e cooperação previsto na legislação educacional brasileira. Contudo, o PME não pode restringir-se à cópia do PNE 
ou PEE, mas definir suas diretrizes e metas, expressando o projeto educacional do município de acordo com suas peculiaridades e necessidades.

Reitera-se que, para a construção da gestão democrática e a institucionalização dos SME, faz-se necessário o fortalecimento dos CME, dos conselhos escolares, dos grêmios estudantis, dos fóruns e das conferências municipais de educação como estratégias e possibilidades de transformações, que poderão propiciar mudanças na realidade da educação dos municípios. Portanto, são imprescindíveis compromissos e vontades coletivas em querer que os mecanismos de participação, reivindicados pelos movimentos populares e educadores comprometidos com a educação pública, conforme preveem as legislações, sejam efetivados na prática dos sistemas e das instituições educativas. Estes aspectos requerem o desenvolvimento de uma nova cultura participativa que provoque mudanças nos sujeitos individual e coletivamente, mesmo que sejam pequenas alterações na prática cotidiana, elas podem ensejar novas formas de organização e gestão da educação que materializem a democracia nas escolas e em outras instâncias sociais.

\section{REFERÊNCIAS}

ABRÚCIO, Fernando Luiz. A dinâmica federativa da educação brasileira: diagnóstico e propostas de aperfeiçoamento. In: OLVEIRA, R. P.; SANTANA, W. (Org.). Educação e federalismo no Brasil: combater as desigualdades, garantir a diversidade. Brasília, DF: Unesco, 2010.

BARBOSA, Lucas Barros. Mapas do Relatório Final da Rede Mapa. São Luís, 2017.

BORDIGNON, Genuíno; GRACINDO, Regina Vinhaes. Gestão da educação: o município e a escola. In: FERREIRA, Naura Syria Carapeto; AGUIAR, Márcia Angela da S. (Orgs). Gestão da educação: impasses, perspectivas e compromissos. São Paulo: Cortez, 2000. p. 147-176.

BRASIL. Constituição da República Federativa do Brasil. 1988. Disponível em: http// www.planato.gov.br/ccivil_03/constituição/principal.htm. Acesso em: jan. 2017.

BRASIL. Lei $n^{\circ}$ 9.394, de 20 de dezembro de 1996. Estabelece as Diretrizes e Bases da Educação. Brasília, DF, 1996.

CABRAL NETO, Antônio; CASTRO, Alda M. D. Araújo. Gestão escolar em instituições de ensino médio: entre a gestão democrática e a gerência. Educação \&. Sociedade, Campinas, v. 32, n. 116, p. 745-770, jul.-set. 2014. Disponível em: http://www.cedes. unicamp.br. Acesso em: set. 2017. 
DOURADO, L. F. A escolha de dirigentes escolares: políticas e gestão da educação no Brasil. In: FERREIRA, N. S. C. (Org.). Gestão democrática da educação: atuais tendências, novos desafios. 6. ed. São Paulo: Cortez, 2008. p. 77-95.

DOURADO, L. F. Plano Nacional de Educação como política como política de Estado: antecedentes históricos, avaliação e perspectivas. In: DOURADO. L. F. (Org.). Plano Nacional de Educação (2011-2020): avaliação e perspectivas. Goiânia: Editora UFG; Belo Horizonte: Autêntica Editora, 2011. p. 45-65

DOURADO, Luiz F.; AMARAL NELSON, C. Financiamento e gestão da educação e o PNE 2011-2020: avaliação e perspectivas. In: DOURADO, L. F. (Org.). Plano Nacional de Educação (2011-2020): avaliação e perspectivas. Goiânia: Editora UFG; Belo Horizonte: Autêntica Editora, 2011. p. 285-315.

DOURADO, Luiz. F. A escolha de dirigentes escolares: políticas e gestão da educação no Brasil. In: Naura Syria Carapeto Ferreira. (Org.) Gestão democrática da educação: atuais tendências, novos desafios. São Paulo: Cortez, 2011. p. 93-115.

FAUSTO, Boris et al. O Brasil republicano: estrutura de poder e economia. 8. ed. Rio de Janeiro: Bertrand Brasil Ltda., 2008. (História geral da civilização brasileira). 8 v.

GOHN, Maria da Glória. Conselhos municipais de acompanhamento e controle social em educação: participação, cidadania e descentralização. In: BELLO, Donaldo; CALDERÓN, Adolfo (Org.). Conselhos municipais e controle social da educação: descentralização, participação e cidadania. São Paulo: Xamã, 2008. p. 97-114.

IBGE. Censo 2017. Brasília: IBGE. 2017a. Disponível em: http://www.ibge.gov.br. Acesso em: 15 jan. 2019.

IBGE. Divisão Geográfica do Estado do Maranhão. Brasília: IBGE. 2017b. Disponível em: http://www.ibge.gov.br. Acesso em: 15 dez. 2018.

NARDI, Elton. Sistemas municipais de ensino e o regime de colaboração entre estados e municípios: por onde vamos? In: Sistema municipal de ensino e regime de colaboração. Flávia Obino Corrêa (Org.). Ijuí: Ed. Unijuí, 2006 p.57-82

RANCIÈRE, Jacques. O ódio à democracia. São Paulo: Boitempo, 2014.

SAVIANI, Dermeval. Sistema nacional de educação articulado ao plano de nacional de educação. In: Revista Brasileira de Educação, v. 15, n. 44, maio-ago. 2010, p. 380-412.

WOOD, Ellen M. Democracia contra capitalismo: a renovação do materialismo histórico. São Paulo: Boitempo, 2011

Texto recebido em 27/06/2019.

Texto aprovado em 18/09/2019. 